\title{
Commentary \\ Hypothalamo-pituitary-adrenal axis activity after intracranial catastrophies: what is enough?
}

\author{
AB Johan Groeneveld, Albertus Beishuizen and Nienke Molenaar
}

Department of Intensive Care and Institute of Cardiovascular Research, VU Medical Center, 1081 HV Amsterdam, The Netherlands

Corresponding author: AB Johan Groeneveld, johan.groeneveld@vumc.nl

Published: 8 January 2009

Critical Care 2009, 13:103 (doi:10.1186/cc7131)

This article is online at http://ccforum.com/content/13/1/103

(c) 2009 BioMed Central Ltd

See related research by Bendel et al., http://ccforum.com/content/12/6/R126

\begin{abstract}
This commentary on a paper by Bendel and colleagues in the previous issue of Critical Care describes the difficulty in assessing the sufficiency of adrenal responses to endogenous, stressinduced adrenocorticotropic hormone (ACTH) release by the pituitary or to exogenous ACTH administration in the critically ill patient in general, and after subarachnoid hemorrhage in particular. It is argued that comparisons with responses under circumstances of equal stress as well as assessments of severity of disease are necessary to judge the sufficiency of cortisol responses to endogenous and exogenous ACTH before treatment is considered. There are no universally applicable cutoff values for cortisol levels and increases in cortisol levels with increasing levels of ACTH - for the diagnosis of relative adrenal insufficiency (or as it is now commonly termed, critical illnes-related corticosteroid insufficiency) following, for example, subarachnoid hemorrhage or other intracranial catastrophes. The paper by Bendel and colleagues is critically discussed in view of these concepts.
\end{abstract}

The expression 'enough is enough' refers to the idea that we can unambiguously decide on what is sufficient in life. The question is whether this also applies to medicine and science, where uncertainties may outweigh certainties. In the previous issue of Critical Care, the sufficiency of hypothalamo-pituitary-adrenal (HPA) function over time following subarachnoid hemorrhage $(\mathrm{SAH})$ is addressed [1]. We interpret the findings by the authors on the basis of increases in circulating adrenocorticotropic hormone (ACTH), but not of circulating cortisol, with increasing clinical severity of $\mathrm{SAH}$, and that some (relative) adrenal insufficiency is present in severely afflicted patients in the acute phase, compared to controls, even though the study does not allow one to determine whether controls (after aneurysm surgery) were equally stressed. In any case, lower cortisol levels than in acute $\mathrm{SAH}$ patients suggest lower stress levels. A comparison with the literature is hard, since there are very few data on acute HPA axis activity after SAH [2].
Indeed, expected responses to stress - caused, for instance, by intracranial catastrophes such as traumatic brain injury and $\mathrm{SAH}$ - would include increases in endogenous ACTH and, thereby, in cortisol secretion relative to normal, unstressed levels, with a concomitant elevation of circulating (total and free) cortisol levels [2-5]. Sufficient adaptation to the stress response would be suggested by parallel increases in ACTH and cortisol levels acording to the degree of stress associated with the severity of disease (assessed by scoring systems) $[2,6,7]$. The ratio between ACTH levels and free cortisol levels, which is expected to be maintained because of feedback activity, could provide an index of adrenal sensitivity to ACTH [5]. Adrenal sensitivity can increase with prolonged stress-induced ACTH stimulation or release of stimulating factors other than $\mathrm{ACTH}$, which cause the ratio to decrease; on the other hand, an increase in the ratio would denote adrenal insensitivity and thus perhaps insufficiency, as the paper by Bendel and colleagues [1] seems to suggest. However, (even free) cortisol levels in serum do not necessarily accurately reflect the rate of adrenal cortisol secretion, and the additive value of determinations of free cortisol levels for the interpretation of the sufficiency of response (to disease severity and/or endogenous $\mathrm{ACTH}$ ) remains unclear $[3,4]$, as is the case in the paper by Bendel and colleagues [1]. When (in)sufficiency of HPA axis activation and ACTH/ cortisol secretion is suspected for a given severity of disease, additional assessment of responses to stimulation tests for determining sensitivity may provide further information with which to judge deviations from non-stressed normality [5]. The response to additional stress can be mimicked by ACTH stimulation, even though (surgical) stress may increase free cortisol levels more than a supraphysiological dose of ACTH [4]. This implies that HPA axis sufficiency can be judged by assessing the sensitivity of adrenal responses to endogenous and exogenous ACTH, the levels of which are determined by 
the severity of disease and direct stimulation, respectively, and which frequently interrelate in a reciprocal manner $[5,7]$. For instance, high baseline (free) cortisol levels associated with severe stress may be associated with some decrease in delta cortisol levels upon ACTH stimulation. Therefore, there are no fixed and universally applicable cutoff points to separate insufficient from sufficient adrenal responses in the critically ill, depending on severity of disease. Hence, although delta cortisol cutoff values have been found to be predictive for (survival) benefits of hydrocortisone treatment in septic shock [7], their use for non-septic patients, including those with $\mathrm{SAH}$, as was done in the paper by Bendel and colleagues and other papers [1,8], makes little sense. Even though similar responses in acute $\mathrm{SAH}$ patients and controls [1] suggest sufficient adrenal responses after $\mathrm{SAH}$, we do not know whether the responses depended on the clinical severity of $\mathrm{SAH}$. Otherwise, sliding responses may contribute to poor acceptance of the ACTH test for adrenocortical function during critical illness.

The causes and consequences, and thus the clinical signficance, of the proposed relative adrenal insufficiency after $\mathrm{SAH}$ as suggested by Bendel and colleagues [1] remain obscure. In any case, patients on etomidate, well known for its suppressive action on the adrenals, were excluded from the study by Bendel and colleagues. Corticosteroids given in the acute phase of SAH do not afford a survival benefit [9], even though hydrocortisone treatment may attenuate hyponatremia, which commonly develops during the course of disease and therapy with hypervolemia and is often attributed to cerebral salt waisting [10]. Nevertheless, the clinical manifestations of relative adrenal insufficiency in the setting of $\mathrm{SAH}$ are largely unknown and require future investigation, but might include vasopressor-insensitive hypotension and hyponatremia in the acute phase. However, the study by Bendel and colleagues [1] does not suggest such associations.

As a late complication in the disease course after $\mathrm{SAH}$ and the resultant damage, secondary HPA axis insufficiency may supervene when the stress of the acute phase has waned and $\mathrm{ACTH}$ release by the pituitary still seems insufficient [2,11-14]. In the study by Bendel and colleagues [1], a follow-up assessment was made at 3 months in $\mathrm{SAH}$ survivors and little evidence for secondary HPA insufficiency was found, in contrast to previous observations, suggesting that insufficiency may be transient in the long term [11-14]. Indeed, some authors suggest that weight gain, growth hormone and gonadal deficiencies in the chronic phase could be explained by (pan)hypopituitarism [2,11-14]. In contrast, low (that is, subnormal) ACTH and cortisol levels early in the course of $\mathrm{SAH}$ in the study by Bendel and colleagues [1] could have been caused by (transient) secondary HPA insufficiency, as also found by others $[2,5]$.

Taken together, the sufficiency of the HPA stress response to intracranial catastrophies remains hard to establish, as exemplified in the paper by Bendel and colleagues [1]. We propose that for judging adrenal sensitivity, HPA (in)sufficiency should be defined in terms of both clinical and laboratory (ab)normalities. The authors of the current paper on SAH [1] only partly succeed in applying the above concepts and potential HPA insufficiency after SAH remains open for further study.

\section{Competing interests}

The authors declare that they have no competing interests.

\section{References}

1. Bendel S, Koivisto T, Ruokonen E, Rinnne J, Romppanen J, Vauhkonen I, Kiviniemi V, Uusaro A: Pituitary-adrenal function in patients with acute subarachnoid hemorrhage: a prospective cohort study. Crit Care 2008, 12:R126.

2. Tanriverdi F, Dagli AT, Karaca Z, Unluhizarci K, Selcuklu A, Casanueva FF, Kelestimur F: High risk of pituitary dysfunction due to aneurysmal subarachnoid haemorrhage: a prospective investigation of anterior pituitary function in the acute phase and 12 months after the event. Clin Endocrinol 2007, 67:931-937.

3. Christ-Crain M, Stolz D, Jutla S, Couppis O, Müller C, Bingisser R, Schuetz P, Tamm M, Edwards R, Müller B, Grossman AB: Free and total cortisol levels as predictors of severity and outcome in community-acquired pneumonia. Am J Respir Crit Care Med 2007, 176:913-920.

4. Christ-Crain M, Jutla S, Widmer I, Couppis O, König C, Pargger $H$, Puder J, Edwards R, Müller B, Grossman AB: Measurement of serum free cortisol shows discordant responsivity to stress and dynamic evaluation. J Clin Endocrinol Metab 2007, 92: 1729-1735.

5. de Jong MF, Beishuizen A, de Jong MJ, Girbes AR, Groeneveld $A B$ : The pituitary-adrenal axis is activated more in non-survivors than in survivors of cardiac arrest, irrespective of therapeutic hypothermia. Resuscitation 2008, 78:281-288.

6. Dimopoulou I, Tsagarakis S, Douka E, Zervou M, Kouyialis AT, Dafni U, Thalassinos N, Roussos C: The low-dose corticotropin stimulation test in acute traumatic and non-traumatic brain injury: incidence of hypo-responsiveness and relationship to outcome. Intensive Care Med 2004, 30:1216-1219.

7. de Jong MF, Beishuizen A, Spijkstra JJ, Groeneveld AB: Relative adrenal insufficiency as a predictor of disease severity, mortality, and beneficial effects of corticosteroid treatment in septic shock. Crit Care Med 2007, 35:1896-1903.

8. Weant KA, Saski-Adams D, Dziedzic K, Ewend M: Acute relative adrenal insufficiency after aneurysmal subarachnoid hemorrhage. Neurosurgery 2008, in press.

9. Feigin VL, Anderson N, Rinkel GJE, Algra A, Van Gijn J, Bennett DA: Corticosteroids for aneurysmal subarachnoid haemorrhage and primary intracerebral haemorrhage (review). Cochrane Database Syst Rev 2005:CD004583.

10. Katayama Y, Haraoka J, Hirabayashi H, Kawamata T, Kawamoto K, Kitahara T, Kojima J, Kuroiwa T, Mori T, Moro N, Nagata I, Ogawa A, Ohno K, Seiki Y, Shiokawa Y, Teramoto A, Tominaga T, Yoshimine $\mathrm{T}$ : A randomized controlled trial of hydrocortisone against hyponatremia in patients with aneurysmal subarachnoid hemorrhage. Stroke 2007, 38:2373-2375.

11. Dimopoulou I, Kouyialis AT, Tzanella M, Armaganidis A, Thalassinos N, Sakas DE, Tsagarakis S: High incidence of neuroendocrine dysfunction in long-term survivors of aneurysmal subarachnoid hemorrhage. Stroke 2004, 35:2884-2889.

12. Kreitschmann-Andermahr I, Hoff C, Saller B, Niggemeier SS, Pruemper SS, Hütter BO, Rohde V, Gressner A, Matern S, Gilsbach JM: Prevalence of pituitary deficiency in patients after aneurysmal subarachnoid hemorrhage. J Clin Endocrinol Metab 2004, 89:4986-4992.

13. Aimaretti G, Ambrosio MR, Di Somma C, Gasperi M, Cannavò S, Scaroni C, Fusco A, Del Monte P, De Menis E, Faustini-Fustinni M, Grimaldi F, Logoluso F, Razzore P, Rovere S, Benvenga S, degli Uberti EC, De Marinnis L, Lombardi G, Mantero F, Martino E, Giordano G, Ghigo E: Residual pituitary function after brain injury-induced hypopituitarism: a prospective 12-month study. $\mathrm{J}$ Clin Endocrinol Metab 2005, 90:6085-6092. 
14. Schneider HJ, Kreitschmann-Andermahr I, Ghigo E, Stalla GK, Agha A: Hypothalamopituitary dysfunction following traumatic brain injury and aneurysmal subarachnoid hemorrhage. JAMA 2007, 298:1429-1438. 